\title{
Malaysian Literature in English: A Critical Companion
}

\author{
Mohamad A. Quayum (Ed.). \\ Malaysian Literature in English: A Critical Companion. \\ Newcastle upon Tyne, UK: Cambridge Scholars Publishing, 2020. vi +287 pp. \\ ISBN 978-1-5275-4929-6 \\ Reviewed by: \\ JESLYN SHARNITA AMARASEKERA \\ Department of English Studies, \\ Faculty of Social Science and Humanities, \\ Tunku Abdul Rahman University College, Malaysia \\ jeslynsa@tarc.edu.my
}

Mohamad A. Quayum's carefully curated volume of essays demonstrates the very essence of what represents the ongoing debate on Malaysian Literature in English: what is the national literary identity of Malaysian literature? While the title boldly suggests that this is a critical companion to Malaysian literature in English, one can note that like in his previous works, Quayum seeks to highlight the main issues that are at the crux of Malaysian writings in English; memory and identity. In his introduction, Quayum takes readers on a walk down memory lane with a brief but succinct historical account of the literary movement and policies in preindependent Malaya as well as independent Malaysia. Ongoing education reforms as well as deliberate changes within the Constitution and law-making policies paved the path to nationalism and indirect segregation of Malaysian writers, as well as the language they chose to write in. Quayum aptly states, that often times the works of Malaysian writers who choose to write in English are overshadowed by those who convey their thoughts in Malay. With such minimal recognition and acknowledgment given to literary works by writers who chose to communicate their thoughts in English, Quayum further adds that "given the choice between their roots and their tongue, many of these writers held on to their tongue and sacrificed their roots" (4). He then goes on to demonstrate the emergence of "voluntary exile" imposed on by writers such as Shirley Geok-lin Lim and Ee Tiang Hong.

Quayum then proceeds to illustrate the ongoing challenges faced by Malaysian writers who proceeded to write in English, either from afar or nearby. Such writers also continued to face hostility given the medium of writing as well as further political differences engulfing the young nation. What can be noted here though is that, regardless of the hostility faced, writers who fell under the "voluntary exile" category on most parts were appreciated and due acknowledgment had been given to their works especially on the global platform. Such acknowledgments are further accentuated in the chapters that follow the introduction. The first of the fifteen chapters within the collection explores existing literary canons within the Malayan context. Rajeev S Patke's Canons and Questions of Value in Literature in English from The Malayan Peninsula provides an exploration of the canons that exist within the Malayan context from colonial as well as postcolonial perspectives. Expanding on the idea of national curriculum development and literary appreciation, Patke concisely deduces that works produced within the Malaysian context serve to feed "rich materials" that can ultimately be used for "testing the feasibility and necessity of a form of literary evaluation that accepts its own contingency while giving the writing the respect its historicity deserves" (27).

Echoing the same thoughts on historical and literary value, Shiley Geok-lin Lim then probes the concept of identity, a perpetual struggle every Malaysian, regardless of gender, race, culture or religion may experience. Her chapter fittingly titled, "English in Malaysia: Identity and the Market Place" demonstrates the ongoing confusion of the bilingual identity 
placed within the Malaysian as well as global market place. Similar trajectories are put forward by Quayum in two different chapters- one dedicated to the poignant works of Lloyd Fernando in which national identities are often at the forefront, and another recognising the MalaysianIndian identity and how it is represented in the works of K. Maniam. While the novels examined and scrutinised may have been written in a different past, the sentiments of the characters continue to represent the marginalised and perplexed voices of the Malaysian community of today. Quayum further interpolates the concept of a plural society, a term that is often synonymous with the Malaysian identity and all its multicultural facets, through his analysis of five different novels and the pursuit of the elusive, unifying national identity.

Boey Kim Cheng and Dennis Haskell also explore identity as presented within selected Malaysian literature in English, emphasising on the exilic writings which cling on to the idyllic past of Malaysia. By exploring the significance of the past, both writers present culture as well as tradition through the memory of place; with Haskell emphasising on Malacca. It is evident that each chapter seems to reflect upon the memories of a past, where both national and diasporic identities interweave as evident in not only the writings of selected writers, but also in their thoughts and opinions. Andrew Hock Soon $\mathrm{Ng}$ explores this interweaving of nostalgia and cultural identity through his exploration of Shirley Geok-lin Lim's poetry. He asserts that the representation of food used in her poetry is "so profoundly infused with strong emotional parameters linked to the memory of kinship and home" (214), there is no denying how significant such nostalgia towards the past can be in terms of creating the diasporic identity.

In Retrieving Lost Histories: Spaces of Healing, Spaces of Liberation, Carol Leon and Gladys Koh stress further on the role of memory and nostalgia through historical fiction. Examining Tan Twan Eng's The Gift of Rain, this essay uses the lens of personal and historical narratives to demonstrate the significance of memory, specifically memory of a place in helping an individual overcome a traumatic past. The pivotal realisation of how influential one's past settings can be is embodied in this quote "Place has an immense psychological impact on an individual. It is a relationship that is complex, at once binding and fragile..." (245). Interestingly enough, another chapter is also dedicated to the works of Tan Twan Eng, highlighting the conflict of having to jostle between the memories of the past while coming to terms with the present. Barnard Wilson provides a contradicting view with regard to memory by pointing out the failures of memory in reinventing and reclaiming identities of both nation and self as demonstrated in Tan Twan Eng's novels. It is pivotal to note that this significantly highlights how Malaysian literature in English, especially those written by the "exile writers" may present a past close to their hearts, but ultimately can be deemed as specular in perspective.

It must be said however, that most of the chapters in this book seem to inspect and scrutinise similar works of the same prominent Malaysian writers. This is rather unfortunate considering the fact that the past 10 years have seen the rise of various Malaysian writers such as Shih-Li Kow, Hanna Alkaf, YZ Chin and Saraswathy M. Manickam, who have in their own rights, achieved international recognition for their works. The lack of acknowledgement given to such contemporary writers suggests that the volume falls back on and is thus confined to the works of a select and overtly celebrated few. Therefore, as much as this book sheds light on and duly recognises the brilliance of postcolonial Malaysian writers, it also draws attention to the dire need for critical volumes that focus on a more expanded list of literary works emerging from the Malaysian nation. 